\title{
Comprehensive evaluation of high-steep slope stability and optimal high-steep slope design by 3D physical modeling
}

\author{
Xing-ping Lai ${ }^{1)}$, Peng-fei Shan ${ }^{1)}$, Mei-feng Cai ${ }^{2,3)}$, Fen-hua Ren ${ }^{2,3)}$, and Wen-hui Tan ${ }^{2,3)}$ \\ 1) School of Energy Engineering, Xi'an University of Science and Technology, Xi'an 710054, China \\ 2) School of Civil and Environmental Engineering, University of Science and Technology Beijing, Beijing 100083, China \\ 3) Key Laboratory of the Ministry of Education of China for Efficient Mining and Safety of Metal Mines, University of Science and Technology Beijing, Beijing 100083, \\ China \\ (Received: 6 June 2014; revised: 12 September 2014; accepted: 15 September 2014)
}

\begin{abstract}
High-steep slope stability and its optimal excavation design in Shuichang open pit iron mine were analyzed based on a large 3D physical simulation technique. An optimal excavation scheme with a relatively steeper slope angle was successfully implemented at the northwest wall between Nos. 4 and 5 exploration lines of Shuichang Iron Mine, taking into account the 3D scale effect. The physico-mechanical properties of rock materials were obtained by laboratory tests conducted on sample cores from exploration drilling directly from the iron mine. A porous rock-like composite material was formed for the model, and the mechanical parameters of the material were assessed experimentally; specifically, the effect of water on the sample was quantitatively determined. We adopted an experimental setup using stiff modular applied static loading to carry out a visual excavation of the slope at a random depth. The setup was equipped with acoustic emission (AE) sensors, and the experiments were monitored by crack optical acquirement, ground penetrating radar, and close-field photogrammetry to investigate the mechanisms of rock-mass destabilization in the high-steep slope. For the complex study area, the model results indicated a clear correlation between the model's destabilization resulting from slope excavation and the collected monitoring information. During the model simulation, the overall angle of the slope increased by $1-6$ degrees in different sections. Dramatically, the modeled excavation scheme saved over 80 million tons of rock from extraction, generating enormous economic and ecological benefits.
\end{abstract}

Keywords: slope stability analysis; excavation; design; three-dimensional models; physical simulation

\section{Introduction}

Many approaches such as engineering-geological analysis, the limit equilibrium method and numerical simulation are used to analyze the high-steep slope stability of open pit mines [1-5]. In addition to the simple and fundamental questions that need answering, the theoretical methods used for evaluating cumbersome $3 \mathrm{D}$ problems in practical geotechnical engineering need to be improved. The methods are also insufficient to analyze the discontinuous properties of rock masses. In sharp contrast with theoretical analysis, physical modeling is one of the most useful approaches in rock mechanics with unique advantages for the study of high-steep slope stability [6-10]; in particular, a large 3D physical modeling experiment can accurately provide deformation and fracture characteristics of rock masses in the slope being prerequisite for the prediction of dynamic destabilization and quantitative excavation design of high-steep slopes [11-15].

It is necessary to improve the accuracy of modeling experiments in order to gain a better understanding of the mechanical properties of modeling materials and quantitatively determining the material components [16-17]. We have obtained basic geotechnical information from Nos. 4 and 5 exploration lines of Shuichang Iron Mine, where the boundary line of the open pit mine has already moved $1400 \mathrm{~m}$ towards the west, and the excavation level of the open pit has fallen dramatically to $-440 \mathrm{~m}$ compared to the former excavation level of $-350 \mathrm{~m}[18]$. Moreover, the similar geometric scale 
was 1:400, representing small scale modeling, thus the modeling experiment was difficult to perform. Various kinds of modeling materials with different mechanical properties have been successively developed by researchers worldwide and used successfully in actual applications; for example, lead oxide adopted for modeling the basic components of rock masses was developed by Bergamo Institute in Italy [19]. In addition, NIOS, IBSCM and MIB were developed by Zhang et al. [20] and Wang et al. [21], Ma et al. [22], and Han et al. [23], respectively. Surely, all of these models have properties similar to those of field rock masses; however, quantitative studies on modeling materials have seldom focused on metamorphic rock masses, which are the host rock masses in the high-steep slopes of Shuichang Iron Mine [24]. To solve the above mentioned problems, we developed new modeling materials that are similar to the rock masses of the high slopes in Shuichang Iron Mine and also built a large-scale simulation model. By equipping the simulation model with acoustic emission (AE) censors and monitoring with crack optical acquirement (COA), ground penetrating radar (GPR), and close-field photogrammetry
(CFP), the destabilization processes of rock mass in the high-steep slope were clearly detected and analyzed. The large-scale model not only includes all of the geological and mechanical complexity of the high-steep slope in the actual open pit iron mine, but also provides a quantitative analysis of the mechanism of high-steep slope destabilization.

\section{Geotechnical site characterization}

\subsection{In-situ geological and mining settings}

Shuichang Iron Mine is located in Qianan City of Hebei Province, China (Fig. 1), about $200 \mathrm{~km}$ northeast of Beijing, the capital of China. The actual excavated ore value is about 12 million tons per year. The district is adjacent to alluvial deposits of the Luan River. The alluvium includes modern channel deposits and flood plain deposits in the form of low alluvial terraces adjacent to the channel and flood plains. These alluvial deposits are composed of interstratified lenses of sand, gravel, silt sand, and silt. The exploratory holes indicated that the thickness of the deposits ranges from 3.0 to $7.0 \mathrm{~m}$, with an average thickness of over $5.0 \mathrm{~m}$.

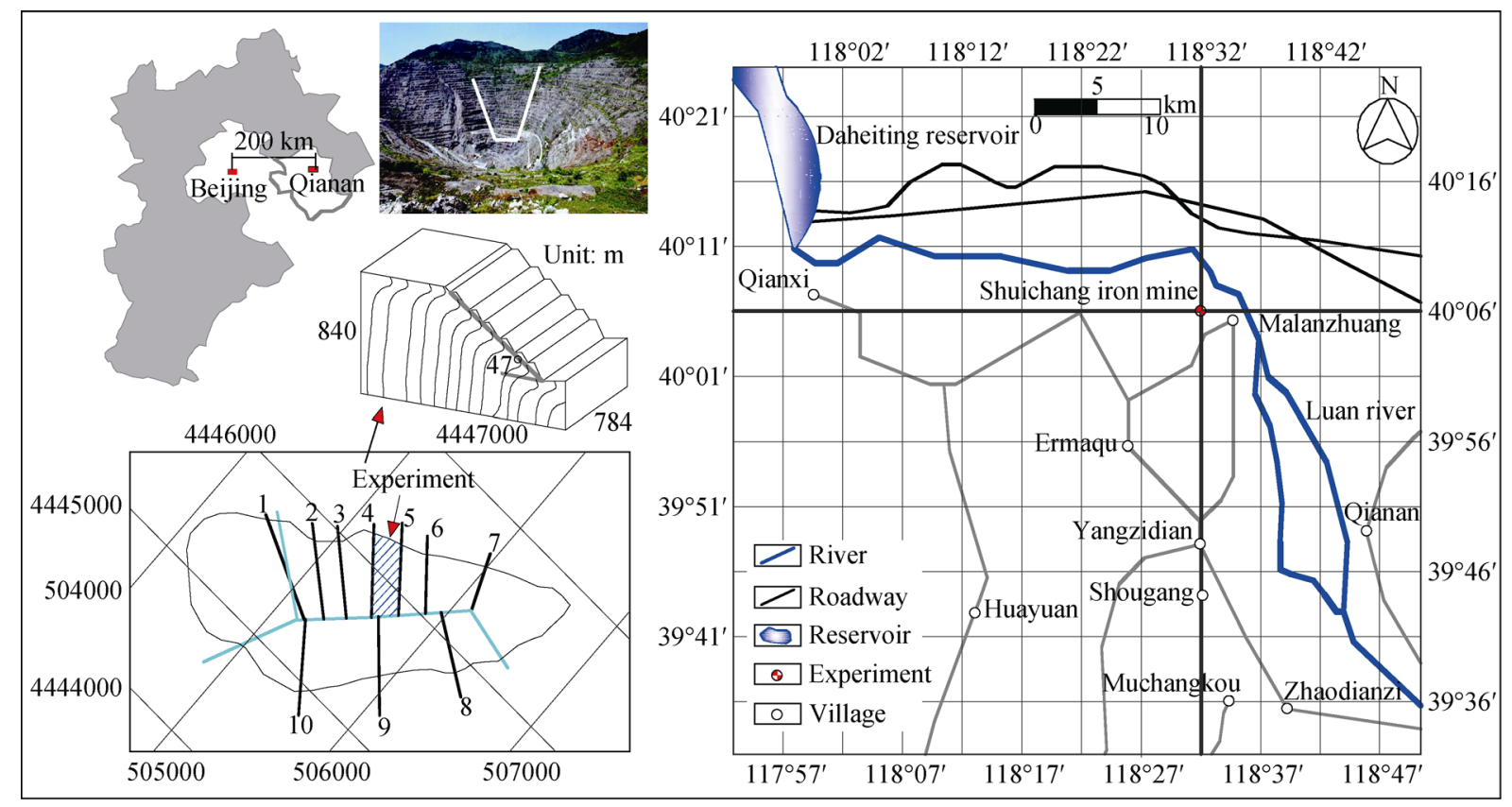

Fig. 1. Situation of Shuichang open pit iron mine in Qianan city of Hebei province, China.

In the current study, we investigate rock slope stability in a typical engineering experiment using a synthetic 3D-analysis method and a large physical modeling experiment, requiring accurate regional geological data. The ore body is sedimentary metamorphic iron ore of the Anshan type. The main strata is metamorphic rock of the three chariot camp group in the Archean Erathem including dark-cloud granu- lite, shallow particle rock, pyroxene dark-cloud granulite, and magnetite quartzite, which are important components of gneiss with different mixing degrees. Waste mining rock serves as artificial fill with a thickness of $80 \mathrm{~m}$ approximately. Particularly during the rainy season, the osmotic pressure derived from the loose structure and strong permeability of the fill results in the easy slippage and collapse of 
the rock slope.

The ore body was controlled by "W" compound synclines composed of Beishan syncline, Nanshan syncline and Jiu Shuichang anticline. At the same time, there are 26 large-scale faults. A couple of preferred planes with dipping angles at $\mathrm{SE} 120^{\circ}-130^{\circ}$ and $\mathrm{SE} 160^{\circ}-170^{\circ}$ are critical causes of landslides. In addition, planes of Jurassic mudstones possessing worse geotechnical conditions develop adverse space relationships with other planes, possibly inducing dynamic disasters in the rock slope.

\subsection{Physico-mechanical properties}

Core samples from five holes at the experimental site were classified using the rock quality designation (RQD) system. This designation system provides a quantitative method of categorizing the engineering traits of rock masses based on core hole information. A summary of the RQD results for the five holes is presented in Table 1, which indicates that the general RQD of open pit mine rock masses is medium. Locally, broken pelagic-gneiss and pyroxene are present with lower RQD.

The physico-mechanical properties of the main metamorphic rock masses used in the large physical models were based on the evaluation of exploratory drilling and laboratory test results. Data utilized in the experiments were ob- tained from the Key Laboratory of the Ministry of Education of China for Efficient Mining and Safety of Metal Mines at the School of Civil and Environmental Engineering of the University of Science and Technology Beijing. The physico-mechanical properties used in the model are summarized in Table 2.

Table 1. Rock quality designation of rock masses in Shuichang open pit iron mine

\begin{tabular}{cccc}
\hline Rock type & RQD/\% & RQD rank & Integrality description \\
\hline $\begin{array}{c}\text { Moderate weathering } \\
\text { pyroxene } \\
\text { Plagiogneiss }\end{array}$ & 21 & Bad & Broken \\
\hline $\begin{array}{c}\text { Conglomerate } \\
\text { Mudstone }\end{array}$ & 78 & Good & Massiveness \\
$\begin{array}{c}\text { Biotite amphogneiss } \\
\text { Dark clouds pyroxene } \\
\text { mixed gneiss }\end{array}$ & 66 & Medium & Relative integrality \\
\hline $\begin{array}{c}\text { Crush mixed granite } \\
\text { Petrofabric }\end{array}$ & 28 & Bedium & Relative integrality \\
\hline $\begin{array}{c}\text { Granite } \\
\text { Dark clouds pyroxene } \\
\text { plagioclase gneiss } \\
\text { Pyroxene }\end{array}$ & 62 & Medium & Relative integrality \\
\hline & 56 & Medium & Relative integrality \\
\hline
\end{tabular}

Table 2. Physico-mechanical properties of main metamorphic rock masses used for physical modeling

\begin{tabular}{ccccccc}
\hline Rock definition & Density / $\left(\mathrm{kg} \cdot \mathrm{m}^{-3}\right)$ & Moisture $/ \%$ & Bulk modulus / GPa & Poisson ratio & Compressive strength / MPa & Tensile strength / MPa \\
\hline Gneiss & 2620 & 2.41 & 4.9 & 0.231 & 110 & 6.3 \\
Granite & 2620 & 0 & 5.3 & 0.217 & 160 & 6.7 \\
Mudstone & 1640 & 3.24 & 0.5 & 0.238 & 20 & 2.6 \\
Ore body & 3750 & 0 & 1.6 & 0.210 & 68 & 4.2 \\
\hline
\end{tabular}

\section{Physical modeling of slope excavation}

\subsection{Physical model simplification}

Physical modeling experiments are measureable research techniques where the physico-mechanical properties of actual rock masses are modeled by manufactured materials that are similar to the actual rocks.

The modeling can provide information by the corresponding experimental phenomena. The main model parameters should be constrained in a non-rigid fashion as:

$C_{\sigma}=C_{r} C_{l}$

$C_{\delta}=C_{l} C_{\varepsilon}$

$C_{\sigma}=C_{E} C_{\varepsilon}$

where $C_{\sigma}$ is the similar ratio of stress, $C_{r}$ is the similar ratio of volume weight, $C_{l}$ is the similar ratio of dimension, $C_{\delta}$ is the similar ratio of displacement, $C_{\varepsilon}$ is the similar ratio of strain, and $C_{E}$ is similar ratio of bulk modulus.

Four kinds of rock masses have been considered in this study: ore body, gneiss, granite and mudstone. Based on the geological section of the slope, we ultimately determined the scope of the simulation to be the slope from No. 4 exploration line to No. 5 exploration line (northwest wall of the district). In the horizontal direction, about $784 \mathrm{~m}$ should be taken into account. The excavation level of the open pit mine has already dropped to $-440 \mathrm{~m}$, suggesting that simulation depth of the slope was $840 \mathrm{~m}$. Simultaneously, the slope angle was altered from $30^{\circ}$ to $47^{\circ}$ in the simulation experiment (Fig. 2). In order to satisfy all experimental requirements, the physical modeling experiment apparatus was constructed with steel and assembled with bolts to ensure rational geometric sizes. The final model size was 3.6 
$\mathrm{m} \times 2.0 \mathrm{~m} \times 2.3 \mathrm{~m}$; specifically, the experimental dimensions of the high-steep slope were $1.0 \mathrm{~m} \times 2.0 \mathrm{~m} \times 1.2 \mathrm{~m}$, and the height of the bottom part was $1.0 \mathrm{~m}$. The lengths of the top and the base of the model were $1.0 \mathrm{~m}$, and the thicknesses of the granite, gneiss and mudstone were $0.38 \mathrm{~m}$, $0.45 \mathrm{~m}$ and $0.75 \mathrm{~m}$, respectively. Considering the deposition environment of the original strata, we established the modeling with $0.01 \mathrm{~m}$ each time. Due to the extensive distribution of faults, the model could not simulate all structural planes; we instead selected faults $\mathrm{F}_{3}$ and $\mathrm{F}_{5}$, which have the greatest influence on slope stability, to emphasize in the model. Furthermore, a coordinate system was used to locate precisely locate the faults in the experiment.

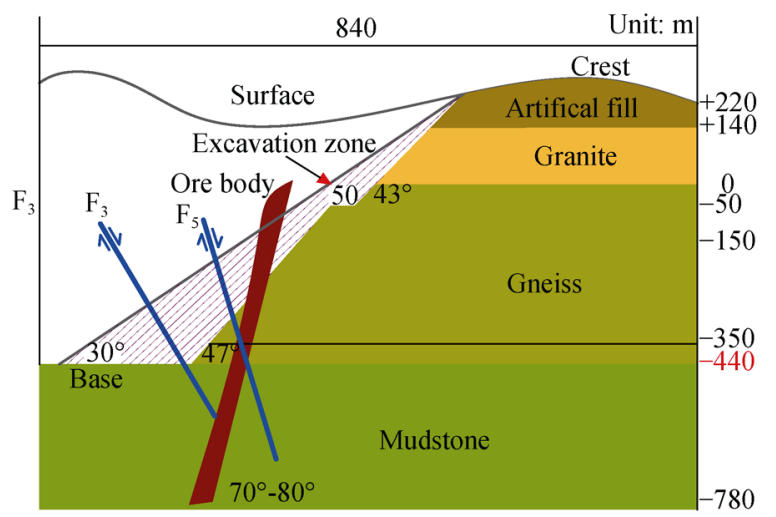

Fig. 2. Simplified geologic model of a high-steep slope for physical modeling.

\subsection{Modeling material determination}

In the present work, we prepared a new kind of modeling material to precisely establish a specific three-dimensional model. For the aggregate, bank sand was used with the following particle size distribution: $3.9 \% \quad 0.50-1.00 \mathrm{~mm}$, $29.1 \% 0.25-0.50 \mathrm{~mm}$, and remainder $0.10-0.25 \mathrm{~mm}$. Gypsum and flour were both used as grouting agents. Water was used as a plastic impact agent, which greatly influenced the accuracy of the material proportions. The porous rock-like composite material (PRCM) was a light material whose density ranged from 1500 to $1700 \mathrm{~kg} / \mathrm{m}^{3}$.

The nonlinear coupling effect of the PRCM is remarkable due to the plastic impact agent. The mechanical properties of PRCM consisting of loose particles are anisotropic, and its comprehensive strength depends on the nonlinear coupling effect with water. On the one hand, various ingredients blend well with water; on the other hand, the alteration of the material by water affects the strength of the modeling materials, and factors such as static pressure $(\mu)$ and hydrodynamic pressure $\left(\tau_{\mathrm{d}}\right)$ should be comprehensively considered. The effective stress of the PRCM $\left(\sigma_{\mathrm{a}}\right)$ could be divided into the following three stages.

Stage I: The modeling material is unsaturated. When external loading is applied in this situation, the pore water does not provide enough internal stress $(\sigma)$ to produce internal micro-cracks and dilatancy in the material, which would decrease its strength. However, along with the increase of water, the unprofitability of static pressure gradually decreases, the strength of the PRCM steadily increases, and the effective stress of the material increases, as expressed by $\sigma_{\mathrm{a}}=\sigma-\mu$

Stage II: The modeling material is saturated. Under external loading, drainage equilibrium process occurs among the internal pores, and the structure of the material is stabilized. Thus, the skeleton and the water jointly bear the external loading. The beneficial static pressure for the skeleton reaches a peak value, making the effective stress of the PRCM material vertex, as expressed by

$\sigma_{\mathrm{a}}=\sigma+\mu$

Stage III: The modeling material is oversaturated. All pores are filled with flowing water, adding extra hydrodynamic pressure that is considered as a type of shear stress. This results in tangential deformation in the skeleton. Micro-cracks evolve into macro-cracks, causing dynamic destabilization and damaging the entire structure. Obviously, the mechanical properties of the PRCM become worse during this process. Meanwhile, the effective pressure decreases sharply, as expressed by

$\tau_{\mathrm{d}}=R \times J$,

in which $R$ and $J$ are the density of the material and the hydraulic gradient, respectively.

The strength of the modeling material was adjusted by altering the aggregate contents. The proportion of the first experimental group was 50:5:5 (aggregate: gypsum: flour); the sand content of the latter group was increased by 5 units compared to the former group. To identify factors affecting the mechanical properties of the modeling materials when the content of water was adjusted, nine specimens $(\phi 50 \mathrm{~mm}$ $\times 100 \mathrm{~mm}$ ) were produced for each group, and experiments were performed in triplicate using $20 \mathrm{~mL}, 30 \mathrm{~mL}$, or $40 \mathrm{~mL}$ of water. Fig. 3(a) shows the stress-strain curves resulting from experiment using a material proportion was 50:5:5; the maximum axial deformation of specimens with $20 \mathrm{~mL}$ of water was $1.6 \%$ statistically, and they exhibited a significant elastic deformation stage under uniaxial stress. When the amount of water increased to $30 \mathrm{~mL}$ with the same proportion, the specimens were better able to obtain a peak value of stress, and a plastic stage was also apparent. The peak value of specimens with $40 \mathrm{~mL}$ water increased to 0.301 $\mathrm{MPa}$, and the bulk modulus values increased quickly until 
failure. At a proportion of 55:5:5 and a water level of $40 \mathrm{~mL}$, a dramatic peak occurred at peak stress due to energy burst release. Because the sand proportion increased to 60 (Fig. 3(b)), the specimen strength decreased obviously, while the residual strength increased and the peak value was generally small. Fig. 3(c) shows that the strength improved step by
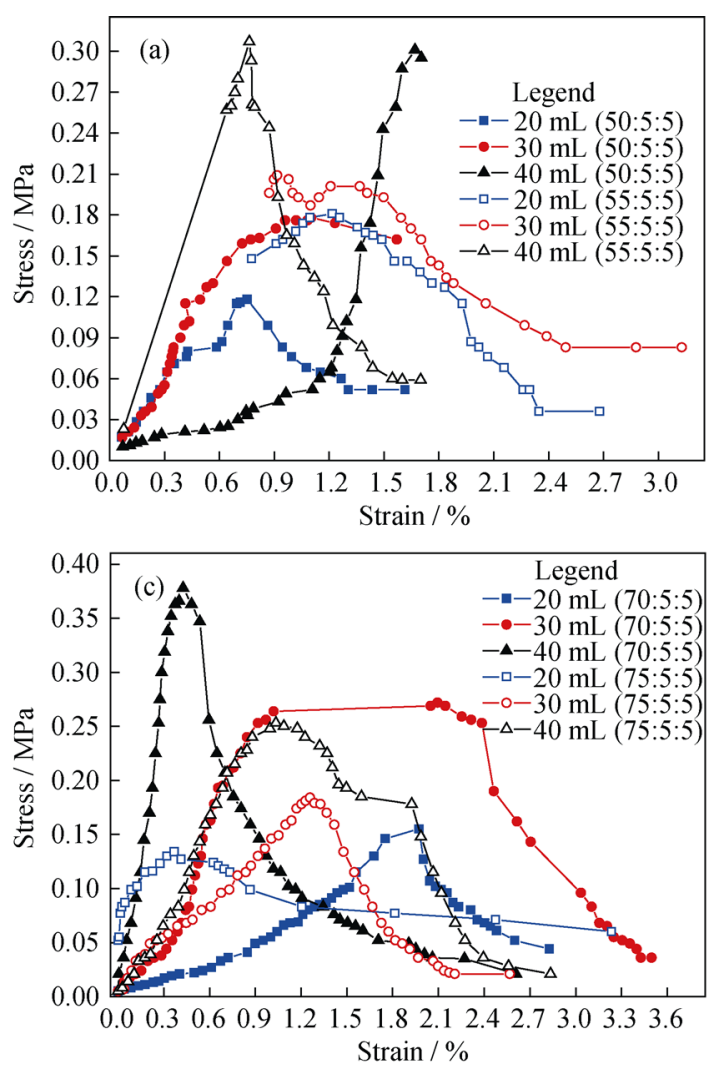

step, reaching a maximum of $0.378 \mathrm{MPa}(40 \mathrm{~mL})$. Meanwhile, stress concentration occurred before sample fracturing with $30 \mathrm{~mL}$ water. With the aggregate proportion further increasing to 80 and 85 (Fig. 3(d)), the specimen ductility at any amount of water was more evident than in the other experiments.
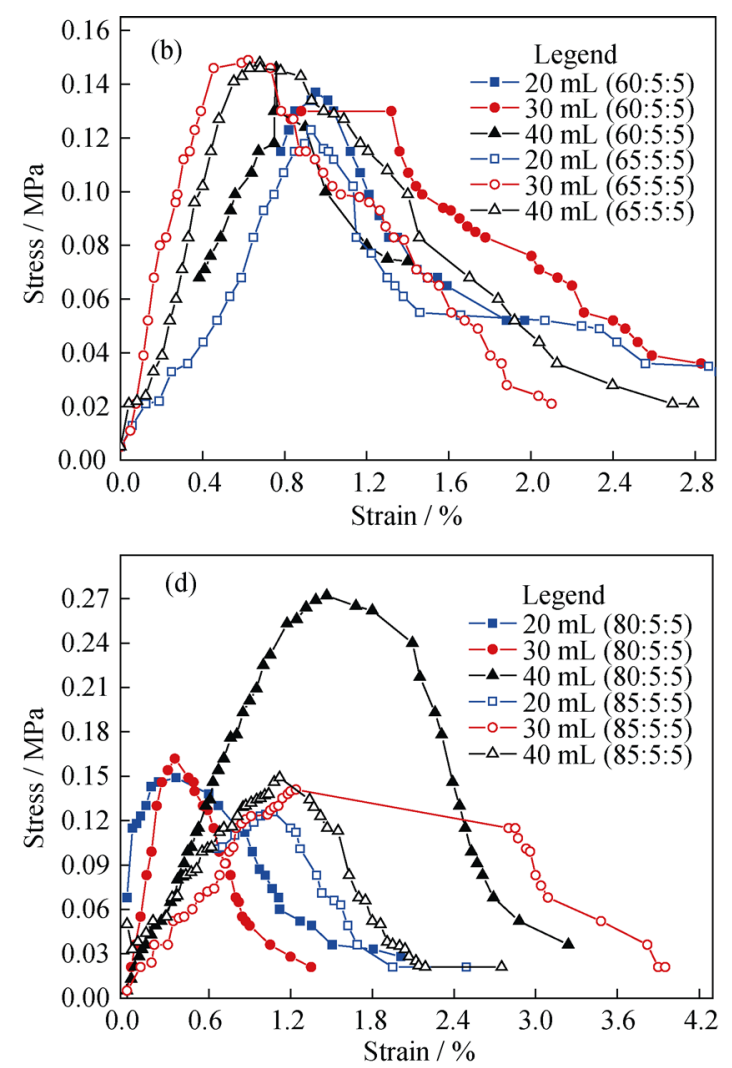

Fig. 3. Stress-strain curves of specimens with various proportions under uniaxial compressive loading (a-d).

The amount of water affects the mechanical properties of the modeling materials. The coupling effects (Fig. 4(a)) from water, aggregate and grouting agents are a quantitative relationship between material proportion and uniaxial compressive stress, and satisfy "dual-saddles" mode with triple maximum values and double minimum ones. Generally speaking, the strength of modeling materials reaches a maximum when the aggregate : gypsum : flour proportion is 70:5:5; in contrast, the strength is the smallest at a proportion of 63:5:5. The addition of more water produces greater volatility in the experimental results. On the other hand, Fig. 4(b) shows that external compressive stress also depends on the water amount, with which specimens statistically get supreme results. Moreover, different proportions are associated with different strain-stress curve shapes; the 60:5:5 and 70:5:5 proportions result in more linear trends, while the 65:5:5 and 85:5:5 proportions produce hyperbolic curves. The other proportions exhibit parabolic trends. The results indicate that bulk modulus values range from 2.0 to 190.0 $\mathrm{MPa}$, while uniaxial compressive stress lies between 0.118 and $0.378 \mathrm{MPa}$, depending on the amount of sand. These results are in agreement with the requirement of small-scale metamorphic rock masses experiment. All experimental proportions are listed in Table 3.

\section{Modeling excavation and hybrid monitoring}

\subsection{Main phenomena of physical modeling}

Fig. 5(a) shows a schematic of the monitoring technique used during the physical modeling experiments. Throughout the experiments, the model was extracted according to different slope angles using an initial angle of $30^{\circ}$. When the slope angle was increased to $33^{\circ}$, macro-cracks first occurred at the slope shoulder. These cracks gradually propagated and connected, resulting in local collapse. Loose deformation formed at the left part of the model shoulder 
along with obvious creep of the rock masses, resulting in serious damage to the excavation plane due to the loosening of the deformation zone (Fig. 5(b)). When the slope angle was increased to $39^{\circ}$, loose deformation affected the bottom of the slope. Inner stress concentration in the rock masses transferred the loading to the slope surface, generating rock mass flow. In addition, the relatively large slope angle increased the tensile stress between layers, resulting in the deformation of rock masses under the action of self-gravity. When the slope angle was increased to $45^{\circ}$, the rate of de-

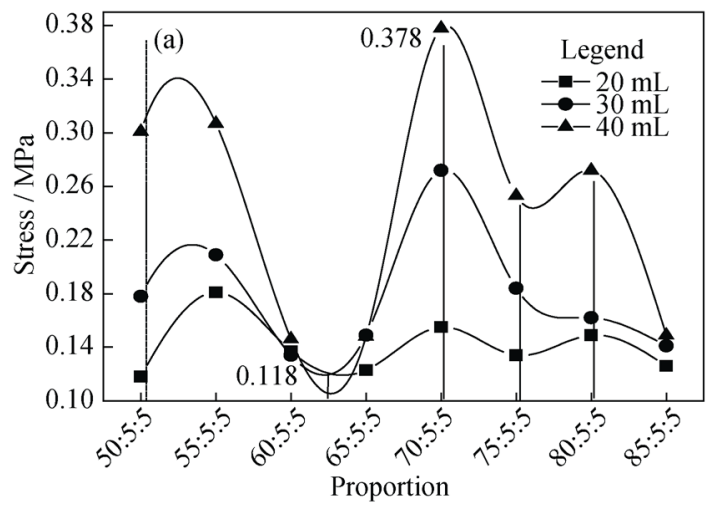

formation and damage accelerated, and the tensile stresses in the slope surface and shoulder reached maximum values. This induced in crack connection and local landslide formation, which were mainly shear-slip landslides. Increases in slope angle caused the shear stress of the surrounding rock to exceed the shear strength on the structural plane. When the slope angle was increased to $47^{\circ}$, the bottom of the slope was dominated by tensile stress. Cracks were propagated to the surface, and large-scale landslides occurred near the geologic structural planes.

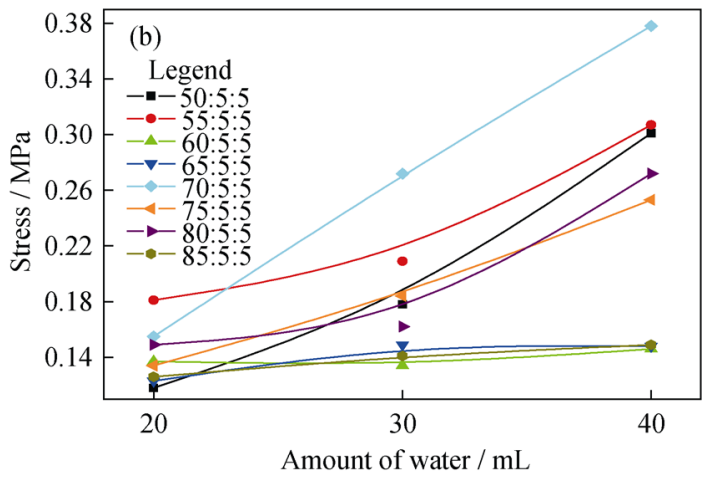

Fig. 4. Mechanical properties of modeling materials influenced by water in various proportions: (a) peak strength curves; (b) trend of peak strength.

Table 3. Experimental results of peak stress, peak strain and residual stress for physical modeling

\begin{tabular}{ccccc}
\hline Proportion & Peak stress / MPa & Peak strain / $\%$ & Residual stress / MPa & Field rock masses \\
\hline $70: 5: 5$ & 0.26 & 0.72 & 0.06 & Granite \\
$77: 5: 5$ & 0.16 & 0.42 & 0.02 & Gneiss \\
$92: 5: 5$ & 0.06 & 0.37 & 0.01 & Mudstone \\
$103: 5: 5(: 10)$ & 0.12 & 0.62 & 0.03 & Ore body \\
\hline
\end{tabular}
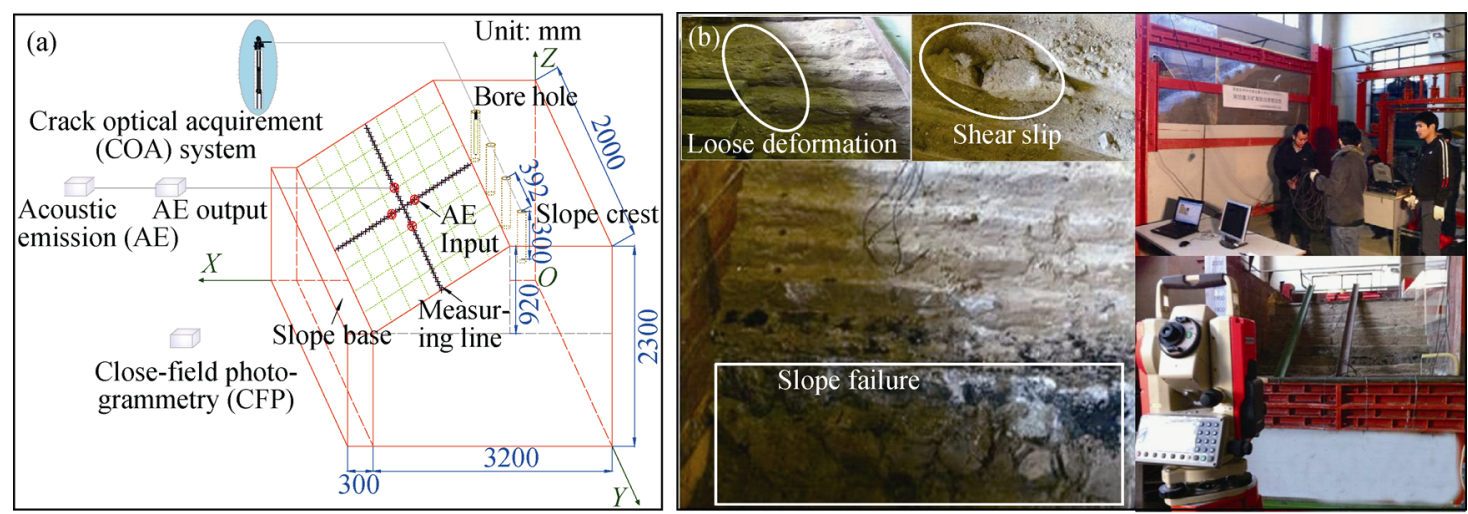

Fig. 5. Monitoring schemes of modeling simulation (a) and main experiment phenomena (b).

\subsection{In-situ real damage monitoring by crack optical ac- quirement}

Crack optical acquirement (COA) was used to quantita- tively describe the deformation and damage of internal strata from pre-designed boreholes. The observation results showed that after three excavations made the slope steeper, remarkable deformation occurred in rock masses surround- 
ing the boreholes. In addition, extreme damage occurred on the shoulder of the slope where rock masses in the borehole wall were stripped, cracks propagated, and the borehole obviously deformed due to stress concentration. Although no overall deformation or failure was observed in boreholes in the central part, micro-cracks occurred. Wholly, deformation and damage occurred on the middle surface of the slope, indicating that the slope surface and internal rock masses were deformed contiguously with the emergence of macro-cracks. In addition, synchronization between the internal and external parts of the model was observed. When the slope angle increased to $47^{\circ}$, dramatically serious deformation and damage occurred in the shoulder of the slope, and key areas of deformation and damage in rock masses moved downwards. Many circular cracks appeared in the middle boreholes, and the diameter of borehole was reduced.
Due to compaction from both the top and bottom parts, landslides occurred in the middle of the slope. On the bottom, the velocities of damage to rock masses accelerated, acting as a prerequisite for landslides. Macro-cracks and joints were classified based on their orientations (Table 4), and a rose diagram of the joints is depicted in Fig. 6(b). We determined eight primary joint orientations: SE120 $-130^{\circ}$, $\mathrm{SW} 200^{\circ}-210^{\circ}, \mathrm{SW} 240^{\circ}-250^{\circ}$, NW300 $-310^{\circ}$, NW340 $350^{\circ}, \mathrm{NE} 10^{\circ}-20^{\circ}, \mathrm{NE} 30^{\circ}-40^{\circ}$, and NE60 $60^{\circ}-70^{\circ}$.

\subsection{Monitoring for damage and fracture of rock masses}

Ground penetrating radar (GPR) data analysis allows geologic parameter determination of rock masses, such as lithology, porosity, water content, and so on. The experimental monitoring zones were divided into six sections for radar scanning in the model. Fig. 7(a) shows the results for the left

Table 4. Statistical information of joint fissure in the bore holes

\begin{tabular}{|c|c|c|c|c|c|c|c|}
\hline $\begin{array}{c}\text { Tendency / } \\
\left({ }^{\circ}\right)\end{array}$ & $\begin{array}{c}\text { Joint } \\
\text { number }\end{array}$ & $\begin{array}{c}\text { Average } \\
\text { tendency / }\left(^{\circ}\right)\end{array}$ & $\begin{array}{l}\text { Average } \\
\operatorname{dip} /\left(^{\circ}\right)\end{array}$ & $\begin{array}{c}\text { Tendency / } \\
\left({ }^{\circ}\right)\end{array}$ & $\begin{array}{c}\text { Joint } \\
\text { number }\end{array}$ & $\begin{array}{c}\text { Average } \\
\text { tendency } /\left(^{\circ}\right)\end{array}$ & $\begin{array}{l}\text { Average } \\
\operatorname{dip} /\left(^{\circ}\right)\end{array}$ \\
\hline $0-9$ & 5 & 6 & 51 & $180-189$ & 2 & 186 & 51 \\
\hline 10-19 & 8 & 15 & 59 & 190-199 & 5 & 193 & 51 \\
\hline $20-29$ & 7 & 24 & 48 & $200-209$ & 9 & 207 & 53 \\
\hline $30-39$ & 8 & 34 & 48 & $210-219$ & 8 & 215 & 40 \\
\hline $40-49$ & 7 & 46 & 51 & $220-229$ & 3 & 223 & 29 \\
\hline $50-59$ & 8 & 58 & 45 & $230-239$ & 13 & 234 & 59 \\
\hline $60-69$ & 10 & 65 & 49 & $240-249$ & 14 & 244 & 55 \\
\hline $70-79$ & 6 & 74 & 55 & $250-259$ & 11 & 256 & 61 \\
\hline $80-89$ & 3 & 83 & 32 & $260-269$ & 12 & 264 & 53 \\
\hline $90-99$ & 10 & 96 & 38 & $270-279$ & 9 & 275 & 60 \\
\hline $100-109$ & 4 & 106 & 39 & $280-289$ & 8 & 285 & 58 \\
\hline $110-119$ & 5 & 115 & 38 & $290-299$ & 3 & 292 & 51 \\
\hline $120-129$ & 17 & 127 & 47 & $300-309$ & 12 & 306 & 59 \\
\hline $130-139$ & 2 & 135 & 48 & $310-319$ & 7 & 315 & 62 \\
\hline $140-149$ & 5 & 147 & 39 & $320-329$ & 5 & 325 & 59 \\
\hline $150-159$ & 5 & 156 & 45 & $330-339$ & 7 & 335 & 65 \\
\hline $160-169$ & 5 & 166 & 44 & $340-349$ & 9 & 343 & 55 \\
\hline $170-179$ & 10 & 175 & 32 & $350-359$ & 7 & 356 & 63 \\
\hline
\end{tabular}
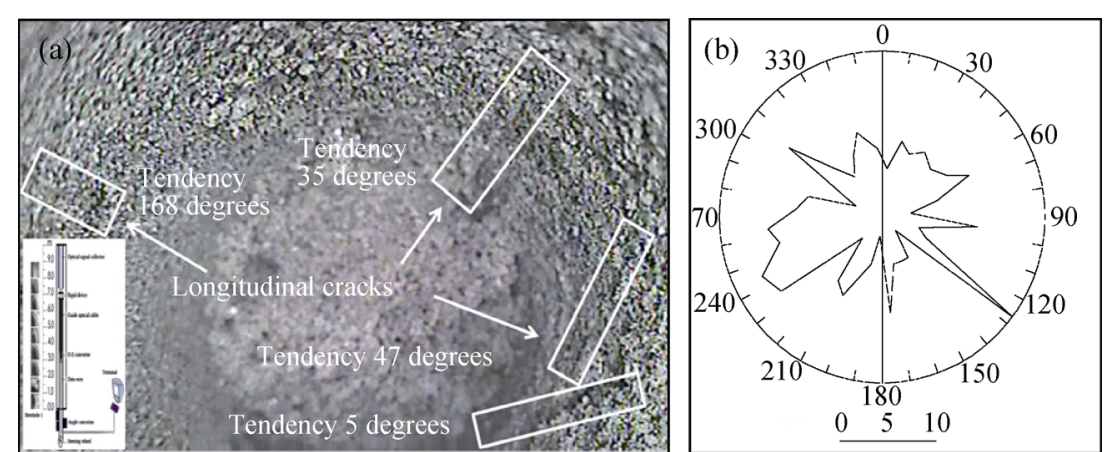

Fig. 6. Image from in-situ real damage monitoring by $\mathrm{COA}$ (a) and rose diagram of joint fissure in the boreholes (b). 

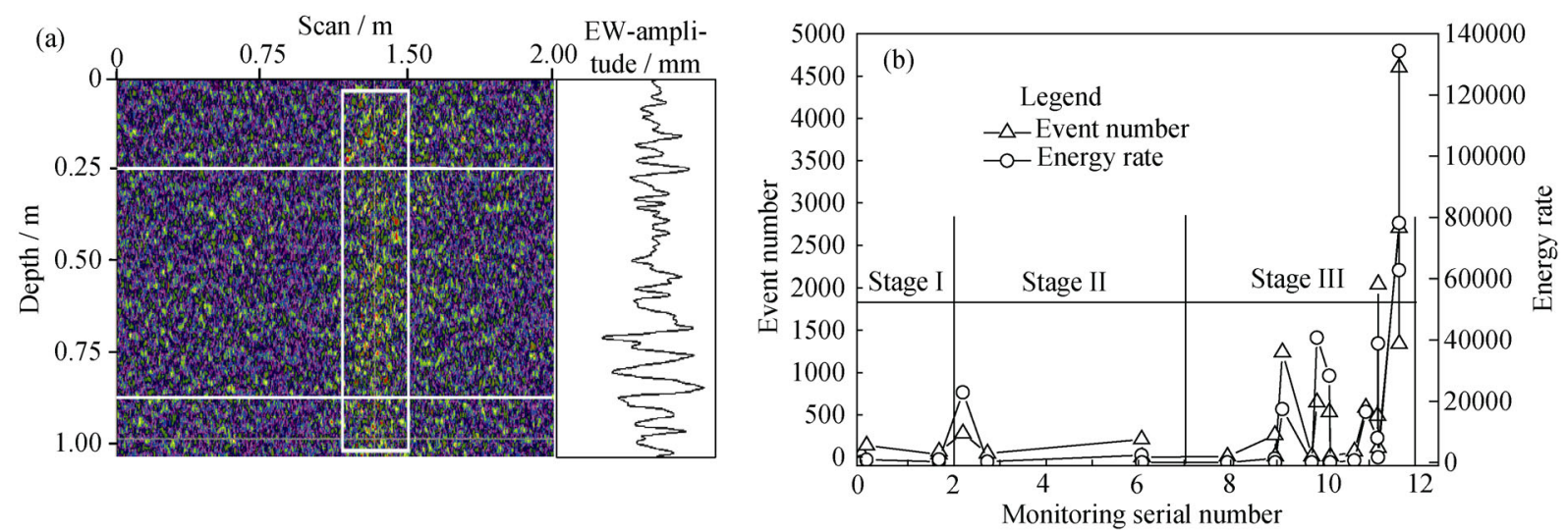

Fig. 7. Damage and fracture data in the excavation of physical modeling: (a) GPR image; (b) AE data.

part on the bottom of the model. At depths from 0 to $0.25 \mathrm{~m}$, the energy of the reflection wave was small, and the reflection wave exhibited many deflections, indicating that rock masses in this range are loose and lack obvious cracks. In contrast, in the depth range of 0.25 to $0.85 \mathrm{~m}$, sudden changes in wave amplitude occurred, indicating the presence of micro-cracks. This suggests that well-developed partial cracks created significant damage due to stretching influences from the loose deformation zone.

Acoustic emission (AE) was adopted to monitor rock fracture in the physical modeling experiments by receiving elastic waves when rock masses were fractured. In total, four AE sensors (\#1, \#2, \#3, and \#4) were set up in the model. The duration of AE monitoring was 375 min during the first excavation; specifically, abrupt wave crests emerged at 11500 and $21000 \mathrm{~s}$. Signals from the \#2 sensor fluctuated and were non-synchronous with low values of both event number and energy rate. These results indicated that the rock masses were stable at that time, and gusty signals represented the occurrence of local failure. The duration of $\mathrm{AE}$ monitoring was $80000 \mathrm{~s}$ when the slope angle increased to $33^{\circ}$. In this period, many occurrences of violent signals were detected by the $\# 3$ sensor. A big event emerged at $4000 \mathrm{~s}$ with an associated increase in energy, indicating a quick decrease in rock strength and significant crack propagation. Later, a significant amount of accumulated energy released, caused several successive local fractures of rock masses. When the slope angle increased to $39^{\circ}$, local cracks became cross-correlated, putting the entire model at risk of sliding. Fig. 7(b) indicates the emergence of many AE signals at $47^{\circ}$, and the curve can be divided into three stages: (1) signals increased slightly due to excavation from 0 to $200 \mathrm{~s}$; (2) energy then accumulated to the maximum at $700 \mathrm{~s}$; and (3) all energy was released from 800 to $1200 \mathrm{~s}$. The peak $\mathrm{AE}$ value occurred at $1200 \mathrm{~s}$ when the rock mass on the bottom of the slope was integrally fractured and moved along the geologic structural planes.

\subsection{Surface displacement monitoring}

Close-field photogrammetry (CFP) was applied to detecting the surface displacement of the model. Figs. 8(a) and 8(b) show overall trend of the slope during excavation including altitude and gradient views of the slope. The first three excavations that made the slope steeper did not induce overall deformation and damage of the slope, although the gradient of sectional areas exceeded the value specified to signal local collapse, and the situation gradually moved towards to the bottom. The altitude views show that the shoulders were more stable than the bottom of the slope, indicating a better synchronic movement of rock masses on the top. In contrast, irregular deformation occurred on the bottom of the rock masses. When the slope angle increased to $47^{\circ}$, both results were unusual; the rock mass on the bottom swelled and separated from the rest of the rock mass. Furthermore, as time passed, more displacement occurred until a landslide happened, at which point the areas of the unusual zones decreased significantly in both slope views.

The displacement values of rock masses at the shoulder of the slope were less in both the $Y$ and $Z$ directions, showing a remarkable nonlinear feature. The values recovered obviously after excavation. At a time of $210 \mathrm{~h}$, the upward displacement reached its maximum value, and the rock masses were in a stage of accumulated positive deformation. At $230 \mathrm{~h}$, the displacement shifted directions, resulting in the downward movement of the entire rock mass. The movement of rock masses at the surface of the slope shoulder was mainly vertical (upwards under early compressive pressure and quick downward sliding later on). The movement along the slope direction was small. The monitoring results of the \#2 sensor indicated that in the middle of the slope, the movement tendency was upwards and forwards due to stretching up and down. The displacement trends in- 
dicated that the rock masses in the middle part of the slope were repeatedly influenced by excavation. The monitoring results of the \#3 sensor showed that on the bottom of the slope, displacement in the $Y$ direction increased sharply for a long time due to sudden energy release. The displacement was positive, indicating that the movement of rock masses on the bottom of the slope was obviously forward. At a time of $220 \mathrm{~h}$, displacement in the $Z$ direction sharply decreased, which indicated that rock masses on the bottom of the slope had already failed due to sliding along weak structural planes (Fig. 8(c)). In conclusion, the deformation and failure of slope rock masses can be divided into three types: (1) extensive fracturing failure on the top of the model; (2) falling failure in the middle of the slope; and (3) failure caused by sliding of the entire rock mass along weak structural planes on the bottom of the model.

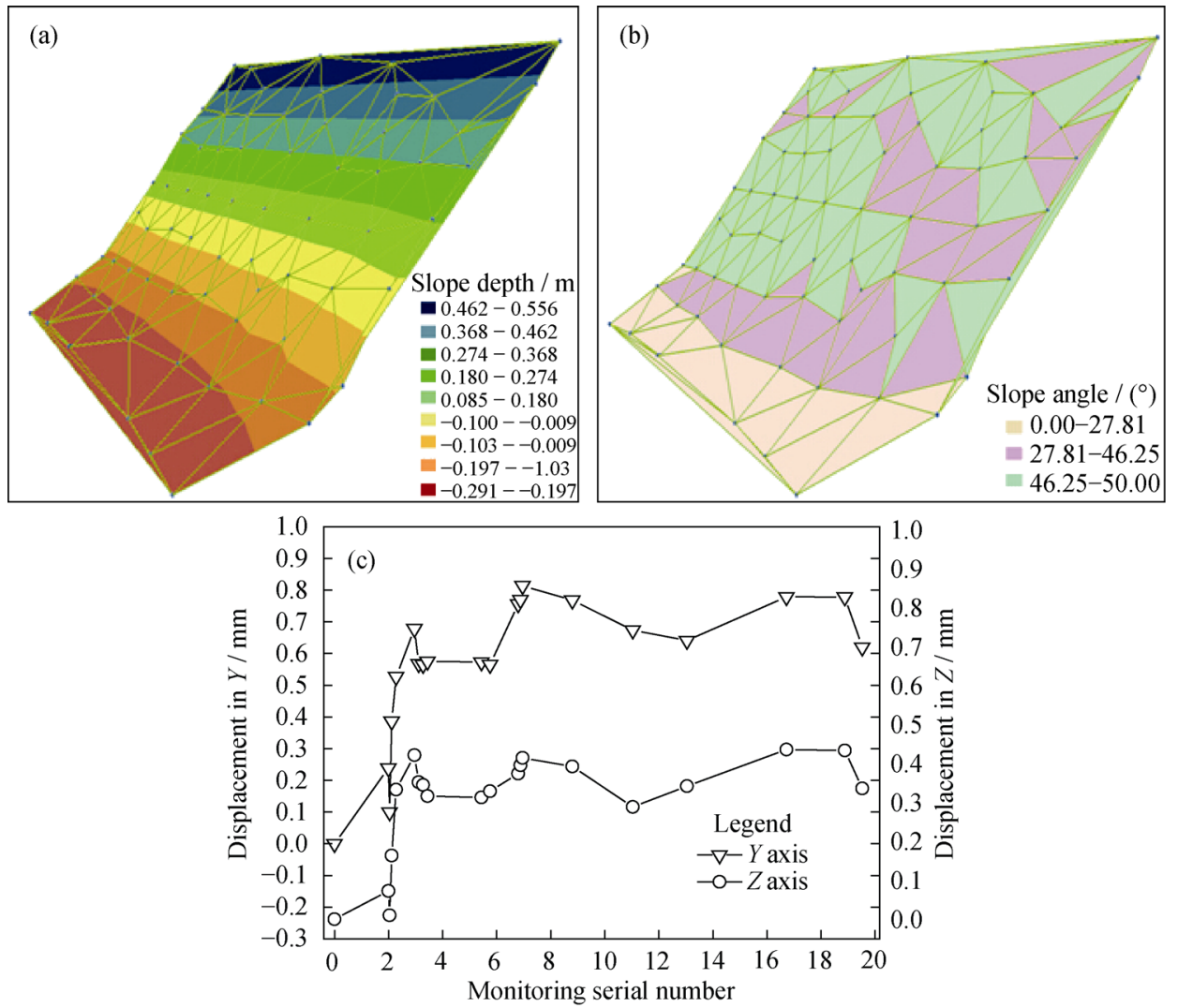

Fig. 8. Displacement analysis of physical modeling from CFP computation (a,b) and specific points monitoring (c).

\subsection{Optimal design of slope angle}

Based on the above physical modeling results combined with the systematical analysis of numerical modeling of slope stability, the overall slope angles of Shuichang open pit iron mine were increased by 1-6 degrees in different sections [5]. In some sections, the rock mass quality was different in the upside and downside of the slope. The downside rock quality was typically better than that of the upside. Thus, the slope angle for the downside was bigger than for the upside in such sections. The demarcation levels of the up and down sides are shown in Table 5. Due to slope angle optimization, the extraction of over 50 million tons of waste rock was avoided, generating remarkable economic and ecological benefits. The final recommended scheme of op- timal excavation for Shuichang open pit mine is also shown in Table 5 .

\section{Conclusions}

(1) A comprehensive site investigation involving hydrogeological, engineering geological, and geotechnical characterization of rock masses in Shuichang open pit mine was carried out. The investigation results showed that the intense rain and significant osmotic pressure induced structural loosening and strong osmotic filling in the slope rock mass, resulting in slippage and collapse of the slope due to the presence of Jurassic mudstone layers.

(2) Based on the field rock mass material characterization, the physico-mechanical properties of the rock masses, and 
the mining excavation design plan, a 3D geologic model of the high-steep slope was built, and a systematic 3D physical modeling experiment was completed. The results showed that the deformation and failure of slope rock masses can be divided into three types: extensive failure at the top of the slope, falling failure at the middle of the slope, and failure caused by sliding of the entire mass along weak struc- tural planes at the bottom of the slope. The results indicated that the landslide would happen in the middle of the slope due to compaction from both the up and down parts. On the bottom, the rate of damage of the rock masses accelerated, providing the conditions for a landslide. In addition, the slope surface and inside rock mass were synchronously deformed.

Table 5. Schemes of optimal excavation design at Shuichang open pit mine

\begin{tabular}{cccccc}
\hline Subregion & Section & Location & Optimal angle $/\left({ }^{\circ}\right)$ & Demarcation level $/ \mathrm{m}$ & Former angle $\left./{ }^{\circ}\right)$ \\
\hline I & I-1 & Upside & 47 & +10 & 46 \\
I & I-1 & Downside & 50 & +10 & 46 \\
I & I-2 & Upside & 43 & +50 & 41 \\
I & I-2 & Downside & 45 & +50 & 41 \\
I & I-3 & Upside & 43 & +10 & 41 \\
I & I-3 & Downside & 49 & +10 & 41 \\
II & II-1 & Upside & 45 & -50 & 46 \\
II & II-1 & Downside & 47 & -50 & 46 \\
II & II-2 & Upside & 45 & -111 & 46 \\
II & II-2 & Downside & 48 & -111 & 46 \\
II & II-3 & Upside & 48 & -112 & 46 \\
II & II-3 & Downside & 50 & -112 & 46 \\
III & III-1 & Entirety & 48 & - & 42 \\
IV & IV-1 & Entirety & 41 & - & 40 \\
IV & IV-2 & Upside & 44 & +10 & 42 \\
IV & IV-2 & Downside & 48 & +10 & 42 \\
IV & IV-3 & Upside & 46 & -50 & 42 \\
IV & IV-3 & Downside & 48 & -50 & 42 \\
V & V-1 & Entirety & 46 & - &
\end{tabular}

(3) The combination of 3D physical modeling and 3D numerical modeling experiments provides an effective and suitable method for stability analysis and optimum design of high-steep open pit mines. With the optimized design, the final slope angle of Shuichang open pit mine was increased by 1-6 degrees in different sections. This optimization reduced the stripping waste rock by more than 80 million tons, creating an enormous economic benefit.

\section{Acknowledgements}

The authors gratefully acknowledge the financial support by the National Key Basic Research and Development Program of China (No. 2015CB251600), the Preliminary National Key Basic Research and Development Program of China (No. 2014CB260404), the National Key Natural Science Foundation of China (No. 51034001, No. U13612030) and the Shaanxi Innovation Team Program (No. 2013KCT-16).

\section{References}

[1] M.F. Cai, M.W. Xie, and C.L. Li, GIS-based 3D limit equilibrium analysis for design optimization of a $600 \mathrm{~m}$ high slope in an open pit mine, J. Univ. Sci. Technol. Beijing, 14(2007), No. 1, p. 1.

[2] M.F. Cai, M.C. He, and D.Y. Liu, Rock Mechanics and Engineering, The Science Press, Beijing, 2002, p. 6.

[3] T.H. Yang, F.C. Zhang, Q.L. Yu, M.F. Cai, and H.Z. Li, Research situation of open-pit mining high and steep slope stability and its developing trend, Rock Soil Mech., 32(2011), No. 5, p. 1437.

[4] J.I. Adachi, E. Detournay, and A.P. Peirce, Analysis of the classical pseudo-3D model for hydraulic fracture with equilibrium height growth across stress barriers, Int. J. Rock Mech. Min. Sci., 47(2010), No. 4, p. 625.

[5] M.F. Cai, L. Qiao, C.H. Li, and J.A. Wang, Stability analysis and design optimization of high and steep slope in Shuichang open-pit mine, J. Univ. Sci. Technol. Beijing, 26(2004), No. 5, 
p. 465.

[6] Z.Y. Tan and M.F. Cai, Multi-factor sensitivity analysis of shallow unsaturated clay slope stability, J. Univ. Sci. Technol. Beijing, 12(2005), No. 3, p. 193.

[7] M.F. Cai, H.G. Ji, and J.A. Wang, Study of the time-space-strength relation for mining seismicity at Laohutai coal mine and its prediction, Int. J. Rock Mech. Min. Sci., 42(2005), No. 1, p. 145.

[8] A.H. Lu, X.B. Mao, and H.S. Liu, Physical simulation of rock burst induced by stress waves, J. China Univ. Min. Technol., 18(2008), No. 3, p. 401.

[9] T.B. Li, X.F. Wang, and L.B. Meng, Physical simulation study of similar materials for rockburst, Chin. J. Rock Mech. Eng., 30(2011), Suppl. 1, p. 2610.

[10] K.Z. Wang and Z.K. Li, Study on 3D physical model test of seepage of deep-buried long and large diversion tunnel, Chin. J. Rock Mech. Eng., 28(2009), No. 4, p. 725.

[11] J. Xiao and X.C. Gao, Similar simulation research on stability of open-pit mine slope under complicated geological conditions, Chin. J. Rock Mech. Eng., 25(2006), Suppl. 2, p. 3661.

[12] X.P. Lai, Y.P. Wu, J.T. Cao, Y.N. Fan, Y.L. Zhang, and F. Cui, Experiment on rock mass deformation of large scale 3D simulation in complex environment, J. China Coal Soc., 35(2010), No. 1, p. 31.

[13] Y.S. Pan, M.T. Zhang, L.G. Wang, and G.Z. Li, Study on rockburst by equivalent material simulation tests, Chin. J. Geotech. Eng., 19(1997), No. 4, p. 49.

[14] R. Castro, R. Trueman, and A. Halim, A study of isolated draw zones in block caving mines by means of a large 3D physical model, Int. J. Rock Mech. Min. Sci., 44(2007), No. 6, p. 860.

[15] X.P. Lai, P.F. Shan, F.H. Ren, J.T. Cao, S.J. Miao, and T.H.
Zhang, Application of model material PRCM in simulation experiment on slope stability, Met. Mine, 43(2013), No. 3, p. 1.

[16] Y.M. Lin, Lab of Rock Mechanics, The Coal Industry Press, Beijing, 1984, p. 143.

[17] C. Occhiena, M. Pirulli, and C. Scavia, A microseismic-based procedure for the detection of rock slope instabilities, Int. J. Rock Mech. Min. Sci., 69(2014), p. 67.

[18] Geological Institution of Shougang Mining Corporation, Supplement Exploration Report for Revised Design in Shuichang Open Pit Iron Mine, Geological Institution of Shougang Mining Corporation, Beijing, 2009, p. 58.

[19] X.L. Jiang, J. Chen, S.W. Sun, and N. Li, New material for rock foundation of geomechanical model of Jingping Project, J. Yangtze River Sci. Res. Inst., 26(2009), No. 6, p. 40.

[20] Q.Y. Zhang, S.C. Li, X.H. Guo, Y. Li, and H.P. Wang, Research and development of new typed cementitious geotechnical similar material for iron crystal sand and its application, Rock Soil Mech., 29(2008), No. 8, p. 2126.

[21] H.P. Wang, S.C. Li, Q.Y. Zhang, Y. Li, and X.H. Guo, Development of a new geomechanical similar material, Chin. J. Rock Mech. Eng., 25(2006), No. 9, p. 1842.

[22] F.P. Ma, Z.K. Li, and G.F. Luo, NIOS model material and its use in geo-mechanical similarity model test, J. Hydroelectr. Eng., 23(2004), No. 1, p. 48.

[23] B.L. Han, X.L. Chen, Y.L. Song, and H.M. Li, Research on similar material of rockmass, J. Wuhan Univ. Hydraul. Electr. Eng., 30(1997), No. 2, p. 6.

[24] X.P. Lai, P.F. Shan, F.H. Ren, Q.S. Wang, W.H. Tan, and S.J. Miao, Comparative experiment on strength of multi-media composite similar materials in mine's high and steep Slope, $J$. Xi'an Univ. Sci. Technol., 32(2012), No. 2, p. 135. 